\title{
Impact of media on sleep quality of adolescents
}

\author{
Koreti S. ${ }^{1}$, Eske G.S. ${ }^{2}$, Saxena S. ${ }^{3}$ \\ ${ }^{1}$ Dr. Sunita Koreti, Associate Professor, ${ }^{2}$ Dr. Gunvant Singh Eske, Assistant Professor, ${ }^{3}$ Dr. Shruti Saxena, Post \\ Graduate Student, All authors are affiliated with Department of Pediatrics, G.R. Medical College, Gwalior, MP, \\ India.
}

Address for Correspondence: Dr. Gunvant Singh ESke, Assistant Professor, Department of Pediatrics, G.R. Medical College, Gwalior. Email: gunvant987@gmail.com. Address: Department of Pediatrics, Kamla Raja Hospital, Lashkar, Gwalior. M.P.

\begin{abstract}
Introduction: Sleep disturbanceis an important risk factor for the development of depression during adolescence. Excessive electronic media usage at night was a risk factor for adolescents' sleep disturbance. As late sleep onset can reduce sleep, this sleep/circadian rhythm disturbance may cause brain impairment [1]. We planned to identify sleep quality of school going adolescents as well as predictors on disturbed sleep patterns like Television, Mobile. Methods: A community based cross-sectional analytical study compromising of 1000 school going adolescents between 8 th to 12th standard studying in government and private schools of city of Gwalior for duration 1 year. Questionnaire prepared on Pittsburg Sleep Quality Index guidelines were distributed to them. Results: In our study the most common cause for sleep disturbances among adolescents were night mares (15.4\%) followed by sleep latency more than 30 minutes. Prevalence of poor sleep quality (PQSI score $>5$ ) was more in 15-17 years age adolescents, class standard 11 th and $12^{\text {th }}$ and lower economic status. The mean time of sleeping was $7.1 \pm .67$ hours on weekdays and $7.42 \pm 0.35$ hours on weekends. Increasing usage of mobile internate was found to be singnificantly associated with poor sleep quality in comparison to television watching. Poor sleep has direct corelation with scholastic performance. Conclusion: About one third of the adolescent's population was having poor quality sleep. Increasing use of mobile internate was found to be singnificantly associated with poor sleep quality Poor sleep has direct corelation with scolastic performance. Sleep assessment must be included in the overall assessment of child's well-being.
\end{abstract}

Keyword: Adolescents, Sleep disturbance, Pittsburg Sleep Quality Index, Sleep quality assesment

\section{Introduction}

Adolescence is a period for increased vulnerability for poor mental health, including depression. Sleep disturbance was an important risk factor for the development of depression during adolescence. Excessive electronic media usage at night is a risk factor for both adolescents' sleep disturbance and depression. To better understand the interplay between sleep, depressive symptoms, and electronic media use at night, this study examined changes in adolescents' electronic media use at night and sleep associated with Smartphone ownership. Over last 2 decades, researchers, teachers, parents and adolescents themselves have constantly reported that

Manuscript received: $10^{\text {th }}$ December 2017

Reviewed: $20^{\text {th }}$ December 2017

Author Corrected: $26^{\text {th }}$ December 2017

Accepted for Publication: $31^{\text {st }}$ December 2017 they were not getting enough sleep. This was not because they have decreased requirement of sleep but change in sleeping habits like "enjoying stay up late". Adolescents were in a development stage that involves biological changes and changes in the social roles which have great impact. This has a repercussion on their sleep habits and patterns, since they were in a transition stage between the child sleep pattern and that of the adults.

The study of sleep in this juvenile population was of great interest because it can contribute to knowledge on the external and internal influences in the establishment of sleep pattern [2]. Optimal sleep was essential for mental and physical health; however, many adolescents suffer from several 
problems related to insufficient or poor sleep, from poor cognitive and behavior performance.

Therefore, recognition and treatment of sleep problems were essential to improve adolescent health, productivity and safety.

\section{Aims and Objectives}

1. To identify sleep quality of school going adolescents from $8^{\text {th }}$ to $12^{\text {th }}$ standard.

2. To identify predictors like Television, Mobile on disturbed sleep patterns

3. To study the different pattern of sleep.

\section{Material and Method}

Place of study: Study was done in private and government higher secondary schools of city Gwalior.

Duration: July 2014 To June 2015 (one year. Type of study: Community based cross-sectional analytical study. Sample Size and sampling

\section{Original Research Article}

method: 1000 adolescents. By multi-stage random sampling method sample was selected randomly.

Sample collection: Questionnaire prepared on Pittsburg Sleep Quality Index guidelines were distributed to adolescents between $8^{\text {th }}$ to $12^{\text {th }}$ standard in government and private schools of the city of Gwalior. They were asked to be filled by the students along with their parents on occasions of parent-teachers meetings and taken back on the same day and evaluated.

Inclusion criteria: School going adolescents between $8^{\text {th }}$ to $12^{\text {th }}$ (Government and private schools).

\section{Exclusion criteria}

- Adolescents who have chronic illness and on medication for the illness(excluding sleep medicines)

- Adolescents who were staying away from home and parents.

- Adolescents whose parents had not given written consent.

\section{Result}

The study was conducted in the city of Gwalior in schools both government and private. Total 1000 adolescents of age group between 10 years to 17 years were taken and analyzed. The present study aims to find out two major outcomes. The primary outcome was to determine the sleep qualtiy and sleep distubances among the adolescents and secondary outcome was to determine the associated factors and the impact of media. The proportion of adolescents with assessment of good sleep and poor sleep by the Pittsburgh sleep quality index (PQSI) were $62 \%$ and $38 \%$ respectively.

The Poor sleep quality was found in late adolescents with age group more than 15 years. Out of total adolescents with PQSI score more than 5, 61.5\% were above 15 years of age. Prevalence of poor sleep quality had no gender difference. The most common sleep disturbance among adolescents with poor sleep quality found in the study (each occurring more than thrice a week) wasnightmares (15.4\%), followed by sleep latency more than $30 \mathrm{~min}$ $(13.5 \%)$.

The less common sleep disturbance were sleep walking $(0.6 \%)$ and others $(0.6 \%)$ including bruxwasm and excessive passage of cervical discharge hamperering sleep (graph 1) We studied the effect of television on quality of adolescents sleep. Although out of 1000 adolescents 369 were televisions viewing more than 2 hours and among them only 142 adolescents have poor sleep (38.4\%). But it was found to be non-significant.

The study found no increase in percentage of children with poor sleep quality with increase in the hours of television watching or computer use. There was no significant difference found in sleep quality when compared with presence television in bedroom and outside (graph 3). The use of mobile has increased in the present few years among adolescents. Use of mobiles for more than 2 hours has negative effects on adolescents sleep. PQSI score found $<5$ among 607 students out of 981 student who were using mobile for more than 2 hours either for internet use or for talking, while only 19 adolescents were using mobile phone for less than 2 hours . Out of 19 such adolescents 17 had PQSI Score < 5. Result was highly significant p value 0.013 (Table 1) 
Original Research Article

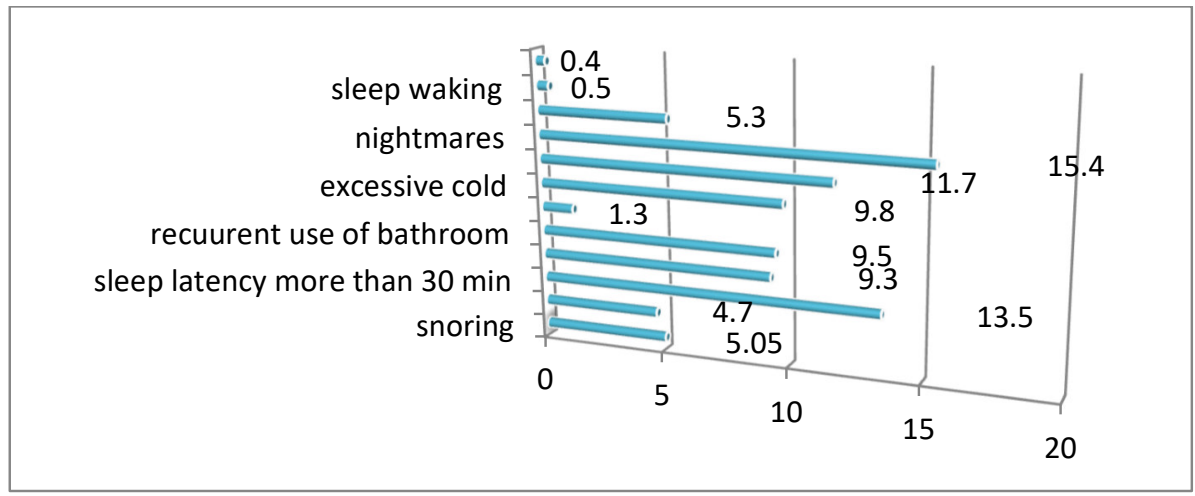

Graph 1: Prevalence among poor sleeping school going adolescents (PQSI score is more than 5)

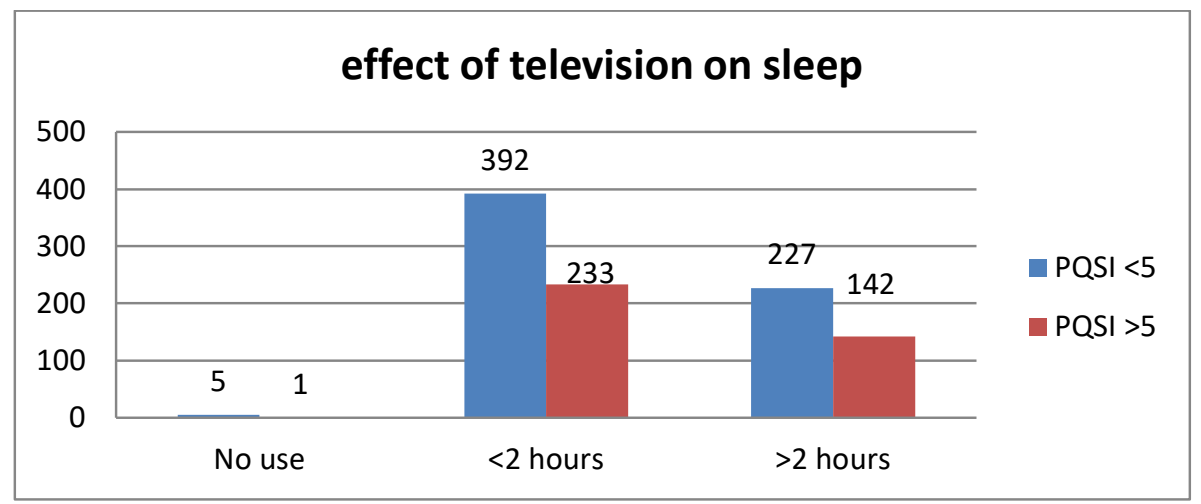

Graph 2: Effect of television on sleep quality

Although out of all adolescents television viewing was more than 2 hours adolescents have poor sleep (38.4\%). But it was found to be non- significant $\mathrm{p}$ value $=0.65$

Table-1: Effect of Mobile use on sleep quality.

\begin{tabular}{|c|c|c|c|}
\hline \multirow{2}{*}{$\begin{array}{c}\text { Mobile } \\
\text { time }\end{array}$} & \multicolumn{2}{|c|}{ PQSI } & \multirow{2}{*}{ Total } \\
\cline { 2 - 4 } & 17 & $>\mathbf{5}$ & 19 \\
\hline Less than 2 hours & 607 & 2 & 981 \\
\hline More than 2 hours & $\mathbf{6 2 4}$ & $\mathbf{3 7 6}$ & $\mathbf{1 0 0 0}$ \\
\hline Total & \multicolumn{2}{|c|}{} \\
\hline
\end{tabular}

$\mathrm{p}$ value $=0.013$ (significant)

Effect of mobile use on sleep quality statically significant

Table-2: Effect of poor sleep on scholastic performance.

\begin{tabular}{|c|c|c|c|}
\hline School grades & $\begin{array}{c}\text { Adolescents with poor } \\
\text { sleep(<5 PQSI) }\end{array}$ & Total no. of adolescents & $\begin{array}{c}\text { Percentage } \\
\%\end{array}$ \\
\hline Grade A & 191 & 567 & $33.6 \%$ \\
\hline Grade B & 169 & 400 & $42.2 \%$ \\
\hline Grade C & 16 & 33 & $48.4 \%$ \\
\hline
\end{tabular}

It was found in the study that poor sleep quality leads to poor grades of adolescents. P value was significant between these 2 groups. On the basis of last 1 month performance. 
We found effect of poor sleep on scholastic performance also. Three groups were made one of grade A, B and C on the basis of last 1-month performance. It was found in the study that poor sleep quality leads to poor grades of adolescents. P value was significant between these 3 groups. Among Grade A students only 33.6\% had poor quality sleep, among Grade B students $42.2 \%$ had poor sleep quality while among Grade C students $48.4 \%$ students were found to have poor quality (table 2)

\section{Discussion}

PSQI : The PSQI was utilized to quantify sleep quality, was properly standardized for retrospective use and applied in Portuguese, and was reliable and employed internationally. The PSQI was validated in Portuguese by A.N. Bertolazi, unpublished data [3]. PSQI evaluates sleep quality during the last month and was composed of 19 (nineteen) selfevaluating items whose overall score ranges from 0 to 20 (zero to twenty), in which the lower the score, the better the sleep quality. Good sleepers were those who obtained a score of less than 5 (five), and poor sleepers were those with scores higher than 5 (five). The PSQI evaluates the items: subjective sleep quality, latency of sleep, duration of sleep, habitual efficiency of sleep, disturbances of sleep, use of drugs and daytime sleepiness Buysse et al. 1989)[4].

A study was conducted in Shanghai Institute for Pediatric Research, Shanghai Key Laboratory of Children's Environmental Health in Shanghai XinHua Hospital, Shanghi Children's Medical Center, and Jiaotong University School of Medicine The method of study was, cross sectional and statistical analysiswas and the sample selected of 19299 elementary - school children, $49.7 \%$ boys and $50.3 \%$ girls, participated in the survey. There was direct co-relation was found between the children with poor sleep quality and their habits of watching T.V. (more than 2 hours). It was found that sleep quality was poor in the children who use mobile for more than 2 hours as compared to those with use for less than 2 hours with statistical significance.

Presence of television in the bedroom and mobile use were directly correlated with late bedtimes, late awakening times, and a shorter duration of sleep during weekdays and weekends. They were also significantly associated with at least 2 types of sleep disturbances. Conclusion was the presence of media in a child's bedroom and media use had a negative effect on children's sleep/ wake patterns, duration of sleep, and sleep disorders [5]. A study done in Wayne State University, US with a sample of 35 men and 36 women between the ages of 18 and 45 years proved exposure to a cellular handset signal for 30 minutes prior to bedtime delayed deep sleep onset by 20 minutes or more, and reduced the total amount of time spent in stage 4 sleep, the deepest and most critical phase of sleep [6].

Result shown that among the 13-year-old children, $13.4 \%$ wake up 1-3 times in a month, $5.8 \%$ wake up once in a week, $5.3 \%$ wake up many times in a week and $2.2 \%$ wake up every night. In the group of 16year-old children, $20.8 \%$ wake up 1-3 times in a month, $10.8 \%$ wake up at least one time in a week, $8.9 \%$ wake up many times in a week and $2.9 \%$ wake up every night [7].

Several hypotheses have been proposed regarding the mechanisms of association between media use and sleep disturbances. First, media use as a form of unstructured activity, which usually lacks a clear beginning and end, is likely to be extended, sacrificing sleep time, and thus shortening sleep disturbances[8]. This sedentary form of entertainment also may alter sleep architecture and lead to poor quality sleep $[9,10]$. Second, exposure to the bright light of the viewing screen before sleep may affect the sleep/ wake cycle through suppression of the nocturnal salivary secretion of Melatonin[11,12,13]. Media use may increase the activity level of the nervous system and result in heightened alertness, physiological arousal, and difficulty falling asleep $[9,11]$.

Television programs may be excessively violent and/or stimulating, which may inhibit relaxation and result in anxiety and difficulty falling asleep [14]. These findings were similar to the result of a survey involving 2546 secondary school children in Belgium, which indicated that television viewing more time per day, more frequent computer game playing and internet use, and the presence of media equipment in the child's bedroom resulted in later bedtimes and awakening times on the weekends and later bedtimes and shorter hours in bed during the week days [8]. Another study involving 1143 Japanese school children aged 6-11 years 
demonstrated that television game playing $\geq 1$ hour/day was linked to sleep deprivation and symptoms of daytime sleepiness[15]. Similarly, a recent study involving 1039 students $10-13$ year old Australian children reported that children with more frequent screen use were likely to sleep less[16]. Previous research involving 495 US school children similarly found that bed timere sistance was most easily affected by television viewing habits, including the amount of television viewing per day $(\mathrm{OR}=2.2)$ and the presence of a television set in the child's bedroom $(\mathrm{OR}=2.4)[14]$.

There was evidence that the sleep onset delay was predominantly influenced by amount of television viewing per day[17,14] and the presence of a television set in the child's bedroom [14]. A study illustrated that only viewing television $\geq 2$ hours/day was a significant risk factor for the sleep onset delay[5]. The present findings may have significant clinical and public health implications. Based on these results, we recommend that both the use of media and the presence of media equipment in a child's bedroom should be limited. This may beneficial to the child's quantity, as well as quality of sleep, and may lead to beneficial changes in a child's daytime performance. Specifically, media use, as a public health problem with the development of society, should be considered as a potential influence on a child's physiological, psychological, emotional, behavioral, and cognitive development.

\section{Conclusion and recommendation}

Sleep quality was assessed by the PQSI score determined by the Pittsburgh sleep quality index. A score more than 5 was considered to be indicator of poor sleep. Out of the total 1000 adolescents included, $37.6 \%$ had poor quality of sleep and $63.4 \%$ had good quality of sleep.

This shows that about one third of the adolescent's population were having poor quality sleep. The most common sleep disturbance among adolescents with poor sleep quality found in the study was nightmares $(15.4 \%)$ followed by sleep latency more than 30 minutes. Increasing use of mobile internate was found to be singnificantly associated with poor sleep quality in comparison to television watching. Poor sleep has direct corelation with scolastic performance.

\section{Original Research Article}

Sleep assessment must be included in the overall assessment of child's well-being. This simple activity takes less than 30 minutes and must be included in school medical check-up activity. Adolescent clinics were opening new door to adolescent medicine to tackle such hidden problems.

What was already known?

- Sleep disturbances were more among girls, children with higher standards $\left(11^{\text {th }}\right.$ and $\left.12^{\text {th }}\right)$

- Most common sleep disturbance found in many study was nocturnal awakening

- Late night television watching, more than 2hours screen time have negative effect on sleep

\section{What study adds?}

- Most common sleep disturbance among adolescents is nightmares.

- Sleep quality is well related with academic performance of adolescents

- Place of television equally affect the sleep quality as duration of any screen time.

- Sleep assessment questionnaire was effective tool in determining sleep-wake which appears to be trivial yet require action.

\section{Declaration}

Funding: Nil, Conflict of interest: None initiated, Perission from IRB: Yes

Contribution details- All three authors were involved in concept, design of study, data collection and critical review.

\section{Reference}

1. Kohyama J. The possible long-term effects of early-lifecircadian rhythmdisturbance on social behavior. Expert Rev Neurother. 2014 Jul;14(7): 745-55. doi: 10.1586/14737175.2014.927735. Epub 2014 Jun 6.

2. Luiz Antonio Del Ciampo, Leda Regina Lopes Del Ciampo, Adolescence and Sleep, Journal of Community and Public Health Nursing, Volume 2 Issue 3.

3. Buysse DJ, Reynolds CF 3rd, Monk TH, Berman SR, Kupfer DJ. The PittsburghSleepQualityIndex: a newinstrument for psychiatric practice and research. Psychiatry Res. 1989 May;28(2):193-213. 
4. National Sleep Foundation. 2006. National Survey on the Sleep Patterns Of United States Adolescents. Sleep in Americans poll highlights key findings [on-line] [20 Jun 2006]:

5. Shengui Li,Xinming Jin, MD1; Shenghu Wu et al, The impact of media use on sleep patterns and sleep disorders among school aged children in CHINA. Sleep Vol. 30,No,3,2007

6. Gabrielsen HR. Insomnia and its predictors in transition from adolescence to adult hood [Serial online]. 2009 [Cited 2010 may 05]; Available from: URL: https://bora.uib. no/bitstream/ 1956/3500/ 1/ 55609437.pdf

7. Text messaging on mobile phones affecting quality of sleep. Latest news and reviews [Serial online]. 2009 September 09[Cited 2010 May 03]; Available from:URL:http://news-reviews.org/ uncategorized/text-messaging-affect-quality-of-sleep

8. Van den Bulck J. Television viewing, computer gameplaying, and Internet use and self-reportedtime to bed and timeout of bed in secondaryschoolchildren. Sleep. 2004 Feb 1;27(1):101-4.

9. Higuchi S, Motohashi Y, Liu Y, Maeda A. Effects of playing a computer game using a brightdisplay on presleepphysiologicalvariables, sleep latency, slow wave sleep and REM sleep. J Sleep Res. 2005 Sep; 14 (3): 267-73.

10. Chen X, Sekine M, Hamanishi S, Wang H, Gaina A, Yamagami T, Kagamimori S. Lifestyles and health-related quality of life in Japanese school children: a cross-sectional study. Prev Med. 2005 Jun; 40 (6):668-78

\section{Original Research Article}

11. Kubota T, Uchiyama M, Suzuki H, Shibui K, Kim K, Tan X, Tagaya H, Okawa M, Inoue S. Effects of nocturnal brightlight on salivamelatonin, corebody temperature and sleep propensityrhythms in human subjects. Neurosci Res. 2002 Feb;42 (2): 115-22.

12. Higuchi S, Motohashi $Y$, Liu Y, Ahara M, Kaneko Y. Effects of VDTtasks with a brightdisplay at night on melatonin, coretemperature, heart rate, and sleepiness. J Appl Physiol (1985). 2003 May;94 (5): 1773-6. Epub 2003 Jan 17.

13. Higuchi S, Motohashi Y, Maeda T, Ishibashi K. Relationship between individual difference in melatonin suppression by light and habitual bedtime. J Physiol Anthropol Appl Human Sci 2005; 24: 419-23.

14. Owens J, Maxim R, McGuinn M, Nobile C, Msall M, Alario A. Television-viewinghabits and sleep disturbance in schoolchildren. Pediatrics. 1999 Sep;104(3):e27.

15. Tazawa Y, Okada K. Physicalsignsassociated with excessivetelevision-gameplaying and sleep deprivation. Pediatr Int. 2001 Dec;43(6):647-50.

16. Olds T, Ridley K, Dollman J. Screenieboppers and extreme screenies: the place of screen time in the time budgets of 10-13 year-old Australian children. Aust N Z J Public Health. 2006 Apr;30(2): 137-42.

17. Paavonen EJ, Pennonen M, Roine M, Valkonen S, Lahikainen AR. TV exposure associated with sleep disturbances in 5- to 6-year-old children. J Sleep Res. 2006 Jun;15(2):154-61.

\section{How to cite this article?}

Koreti S, Eske G.S, Saxena S. Impact of media on sleep quality of adolescents. Int J Pediatr Res. 2017;4(12):721726.doi:10. 17511/ijpr.2017.i12.04. 